\title{
Accurate Evaluation of Active-Site Density (SD) and Turnover Frequency (TOF) of PGM-Free Metal-Nitrogen-Doped Carbon (MNC) Electrocatalysts Using CO Cryo Adsorption
}

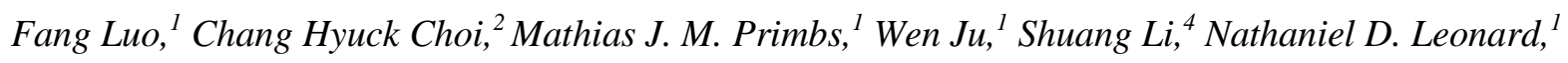
Arne Thomas, ${ }^{4}$ Frédéric Jaouen, ${ }^{*}{ }^{3}$ Peter Strasser ${ }^{* 1}$

${ }^{1}$ Department of Chemistry, The Electrochemical Energy, Catalysis and Material Science Laboratory, Chemical Engineering Division, Technical University Berlin, Straße des 17. Juni 124, 10623 Berlin, Germany

${ }^{2}$ School of Materials Science and Engineering, Gwangju Institute of Science and Technology, Gwangju 61005, Korea

${ }^{3}$ Institut Charles Gerhardt Montpellier, UMR 5253, CNRS, Université de Montpellier, ENSCM, Place Eugène Bataillon, 34095 Montpellier cedex 5, France

${ }^{4}$ Functional Materials, Department of Chemistry, Technical University Berlin, Hardenbergstr.40, 10623 Berlin, Germany 


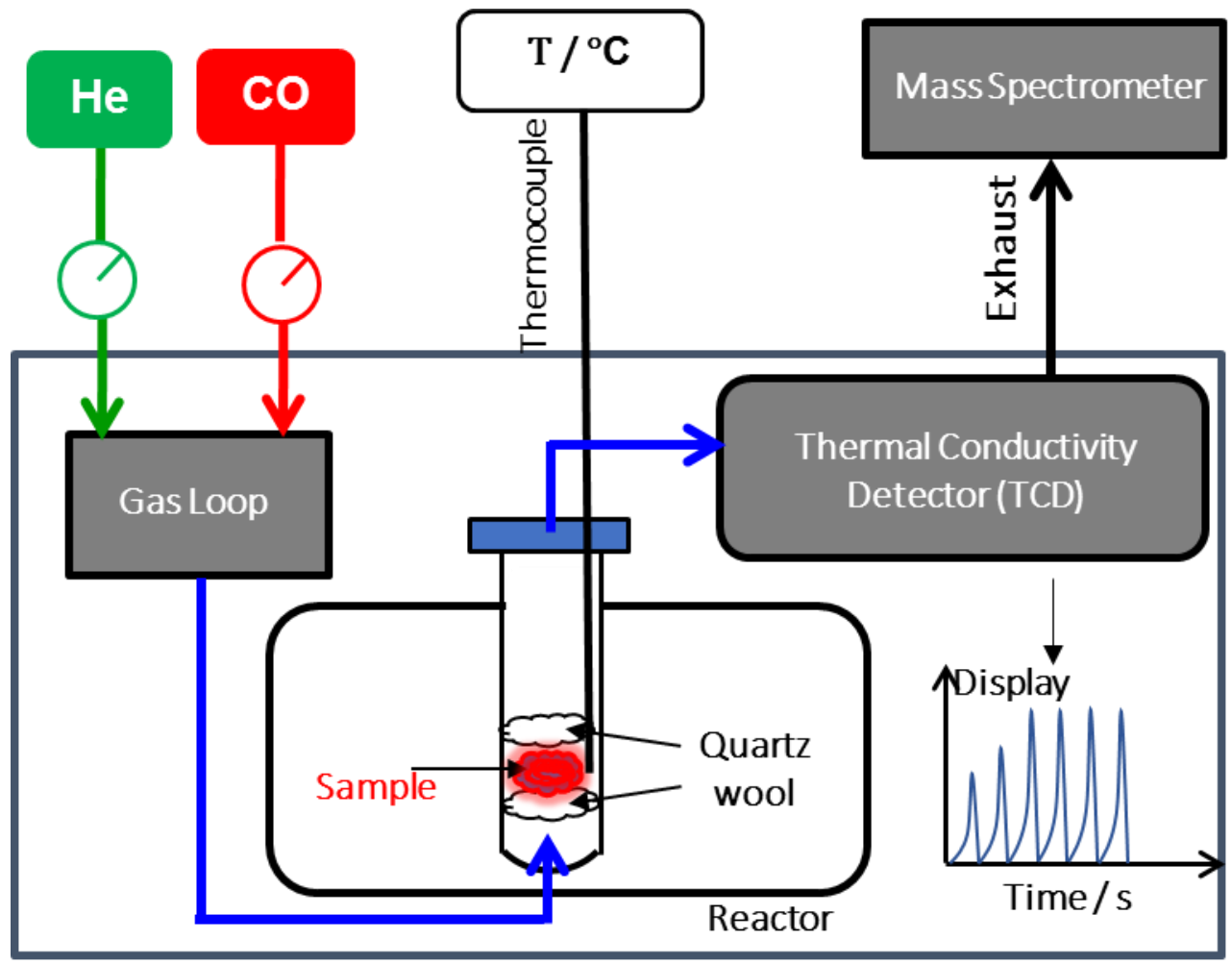

Figure S1. Scheme of the Temperature Programed Reduction and Desorption set up to carry out CO cryo pulse chemisorption and subsequent $\mathrm{CO}$ desorption. 


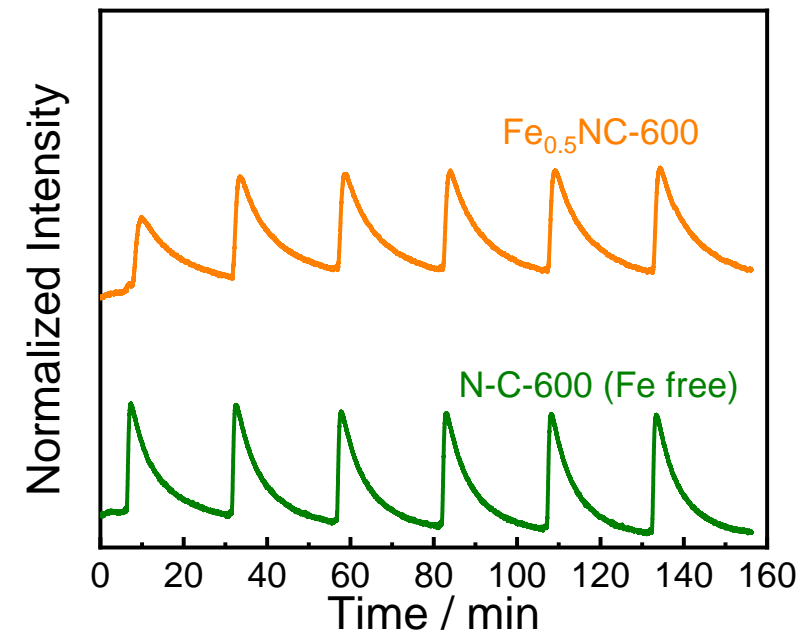

Figure S2. Comparison of the CO uptake trajectories of $\mathrm{Fe}_{0.5} \mathrm{NC}-600$ (top) and the iron-free N-C-600 (bottom) catalysts prepared identically except that no iron precursor was added during the synthesis for the N-C-600. 

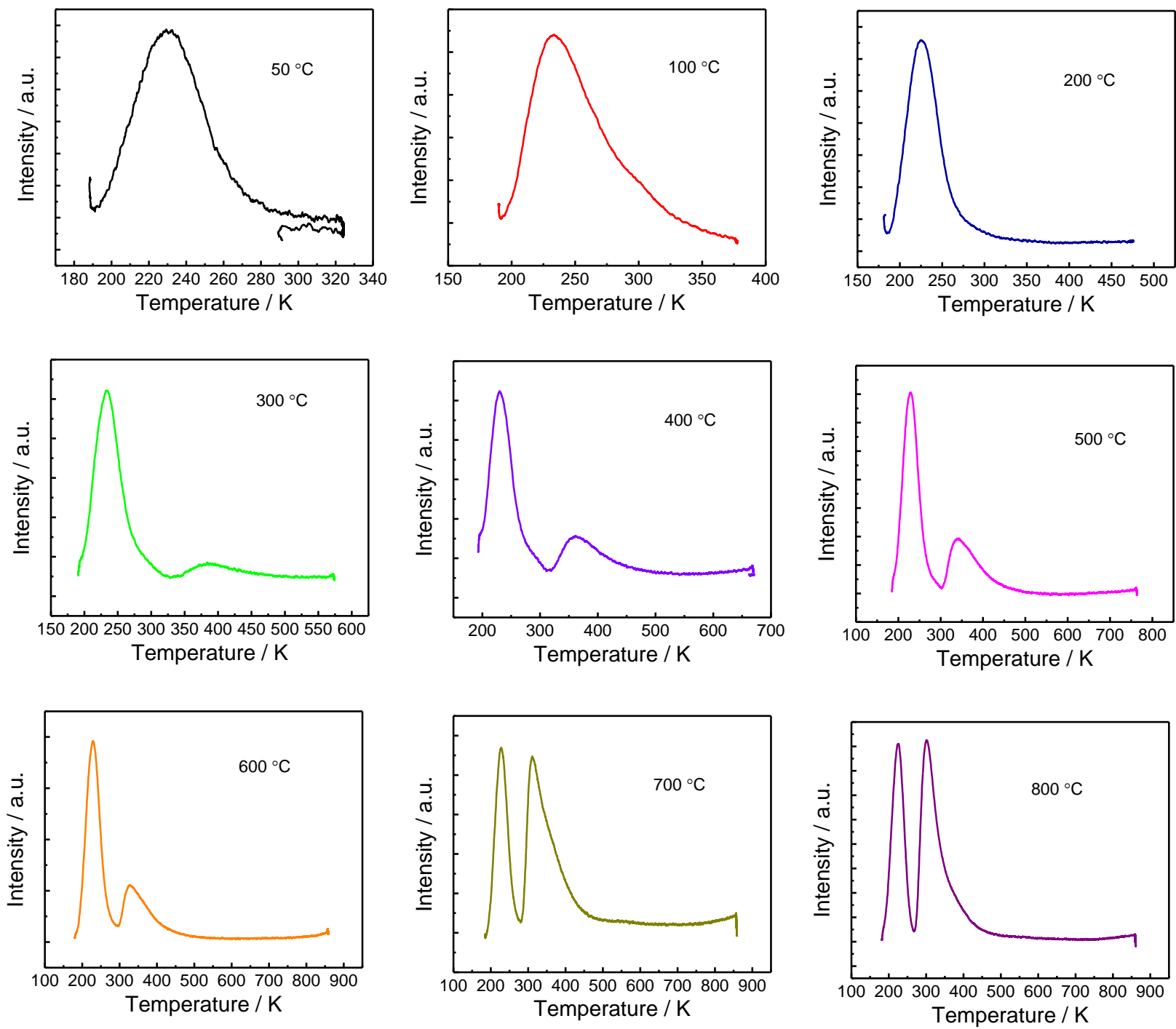

Figure S3. Temperature programmed CO desorption profiles after a cumulative thermal pretreatment protocol of the $\mathrm{Fe}_{0.5} \mathrm{NC}$ catalyst. The highest annealing temperature applied prior to desorption is indicated. 

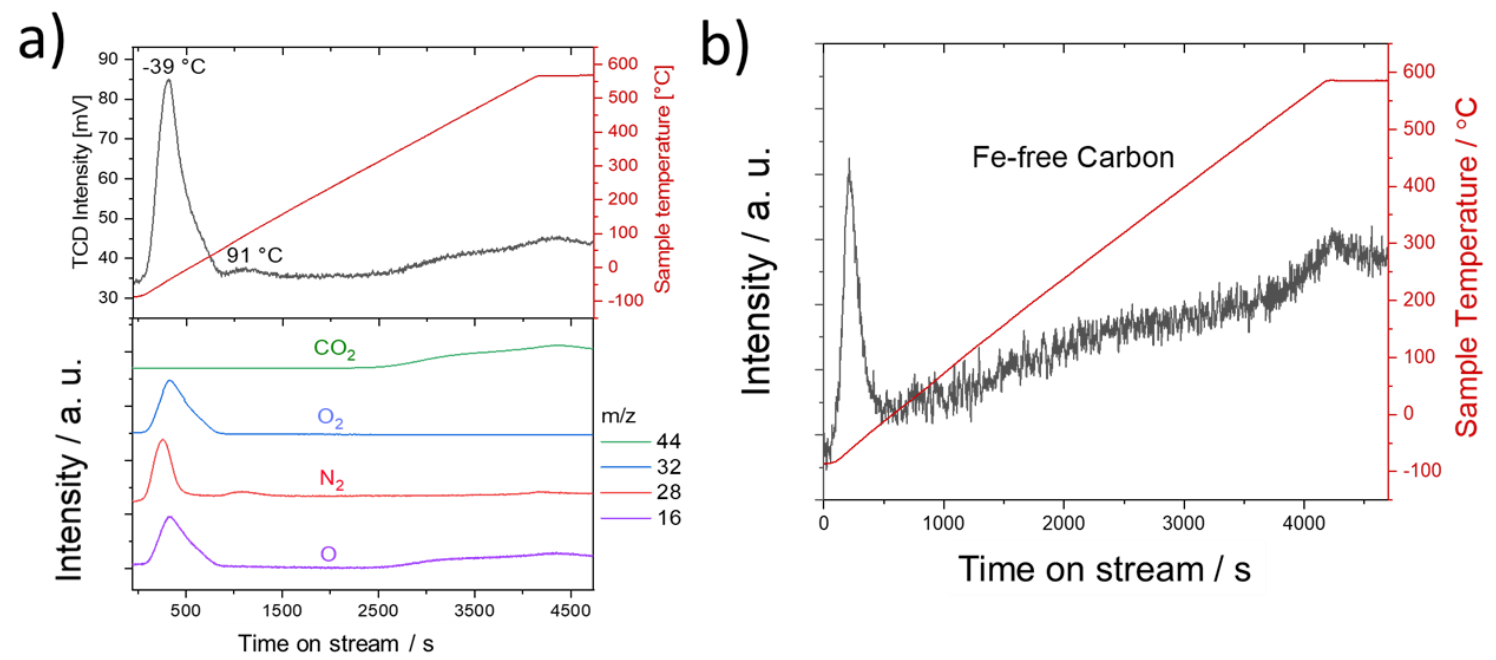

Figure S4. Coupled TPD-Mass spectrometry experiments of (a) the $\mathrm{Fe}_{0.5} \mathrm{NC}$ catalyst and of (b) a Fe-free pure high surface area carbon material in absence of any $\mathrm{CO}$ pulsing under continued He gas flow. Both samples were thermally pretreated at $600{ }^{\circ} \mathrm{C}$ under He. All other details of the sorption/desorption protocol were identical to the protocol applied throughout this work, just $\mathrm{CO}$ pulsing was omitted. Evidently, TPD peak 1 at around $-40{ }^{\circ} \mathrm{C}$ has no relation to $\mathrm{CO}$ ad/desorption, yet is related to release of air from the porous structure. 


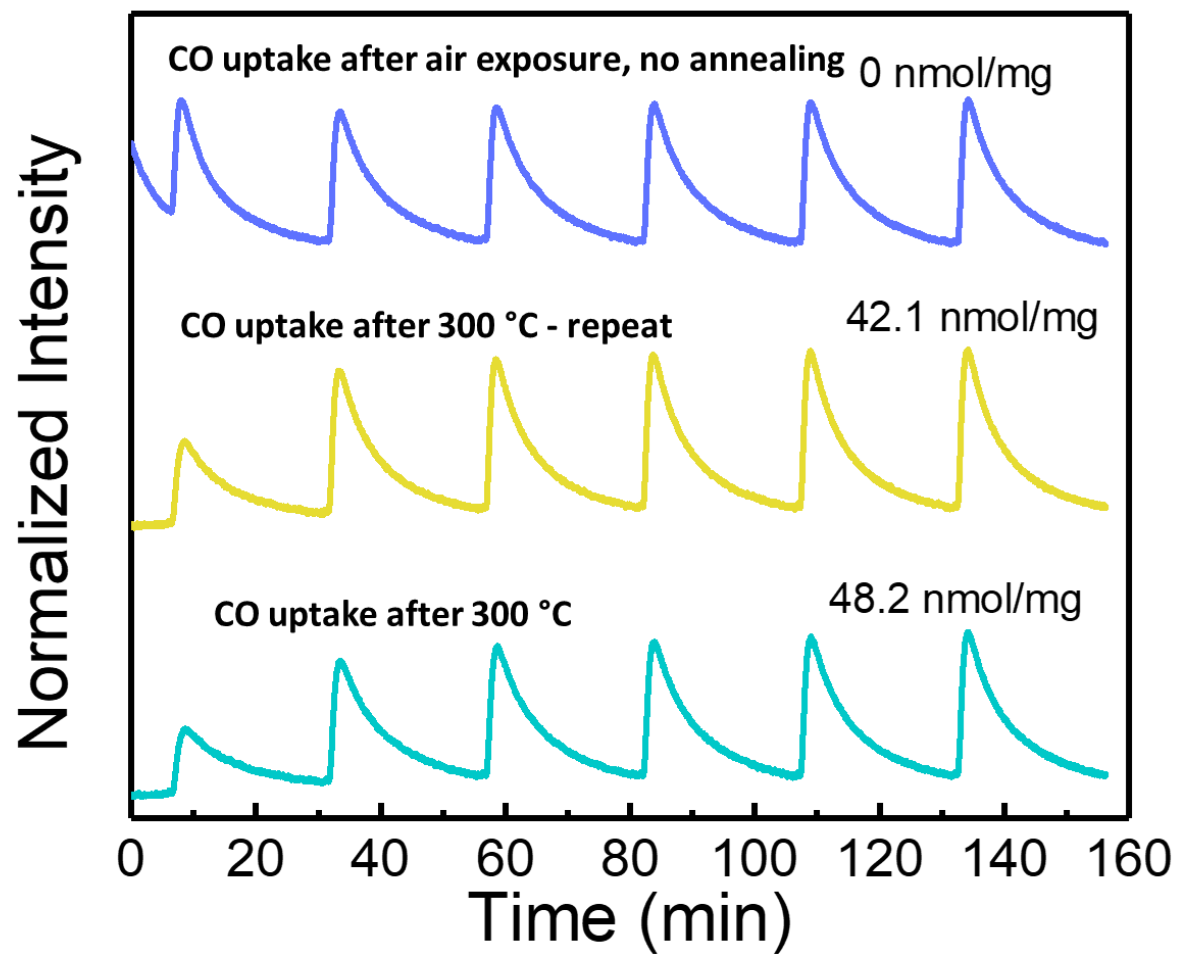

Figure S5. CO uptake (in nmol CO / mg catalyst) of one and the same batch of a $\mathrm{Fe}_{0.5} \mathrm{NC}$ catalyst after thermal pretreatment at $300{ }^{\circ} \mathrm{C}$ (cyan curve, bottom), an immediate repeat (yellow curve, center) and another repeat measurement after exposure to air for 48 hours, and without subsequent thermal pretreatment (blue curve, top). 

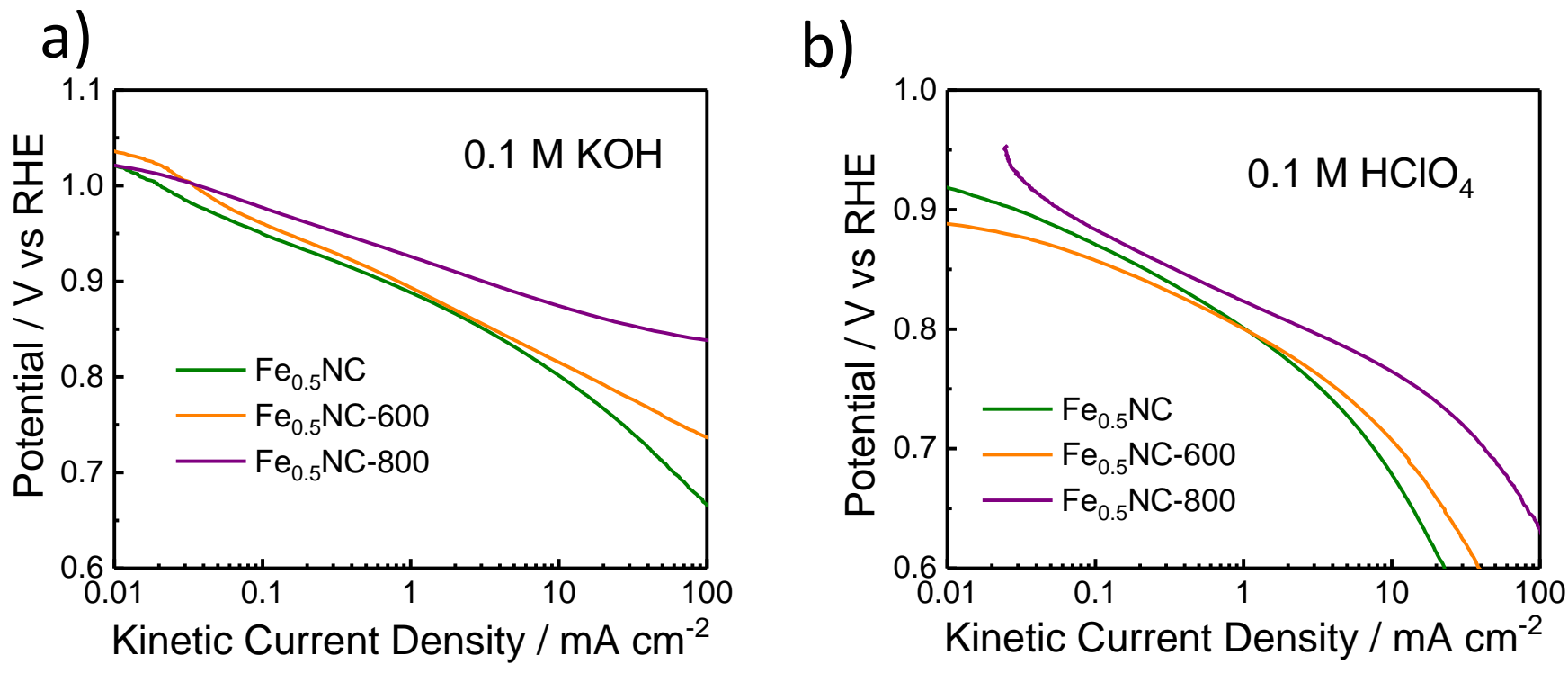

Figure S6. Tafel plots derived from voltammetric curves during catalytic oxygen reduction reaction of $\mathrm{Fe}_{0.5} \mathrm{NC}, \mathrm{Fe}_{0.5} \mathrm{NC}-600$ and $\mathrm{Fe}_{0.5} \mathrm{NC}-800$ in (a) $0.1 \mathrm{M} \mathrm{KOH}$ and (b) $0.1 \mathrm{M} \mathrm{HClO}_{4}$ 
a)

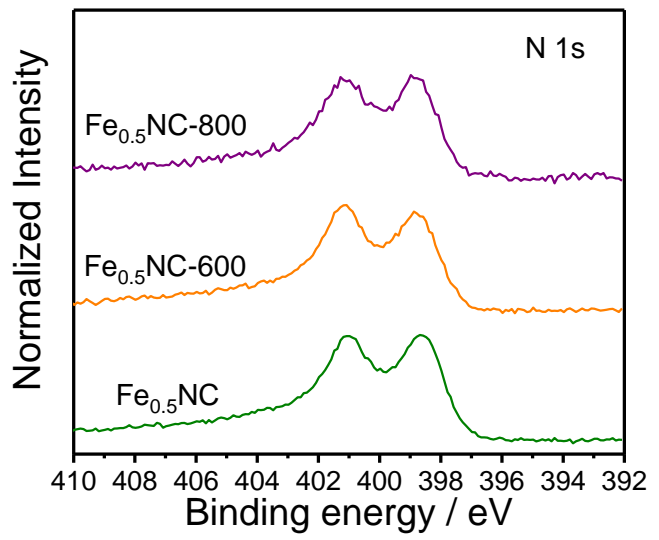

c)

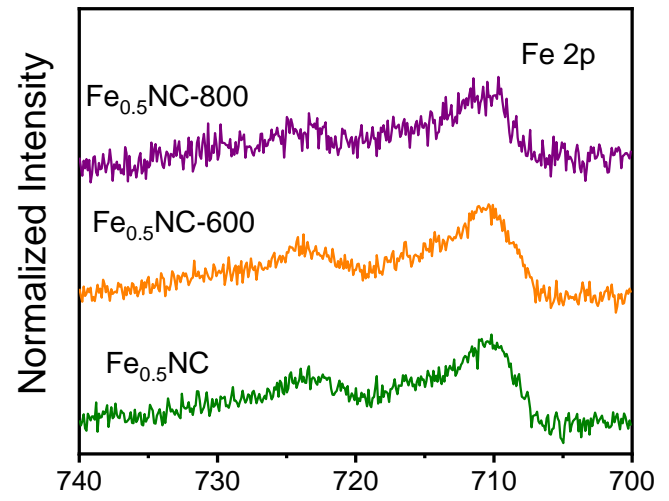

e)

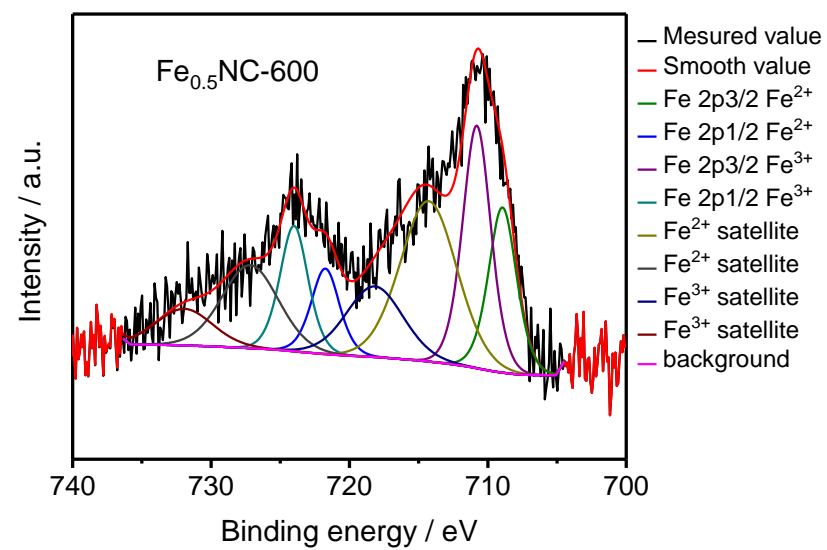

b)

d)

f)
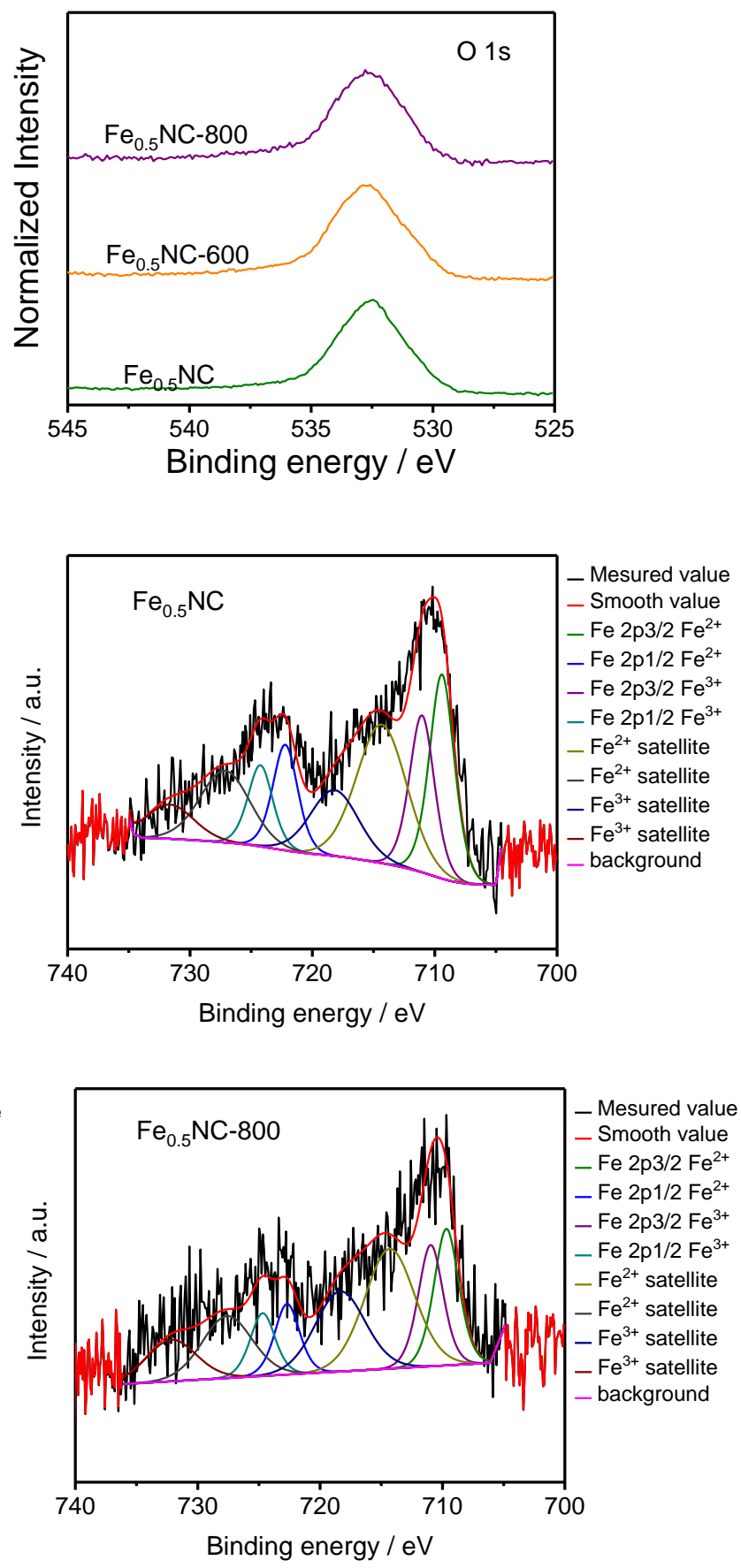

Figure S7. Comparison of the narrow scan X-ray Photoemission spectra at the (a) N 1s, (b) O 1s, and (cf) $\mathrm{Fe} 2 \mathrm{p}$ region for the three catalysts $\mathrm{Fe}_{0.5} \mathrm{NC}, \mathrm{Fe}_{0.5} \mathrm{NC}-600$ and $\mathrm{Fe}_{0.5} \mathrm{NC}-800$. 
a)

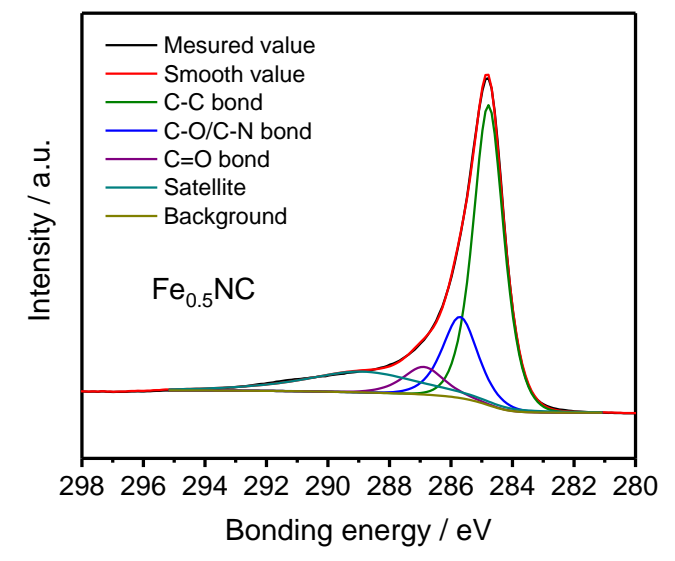

b)

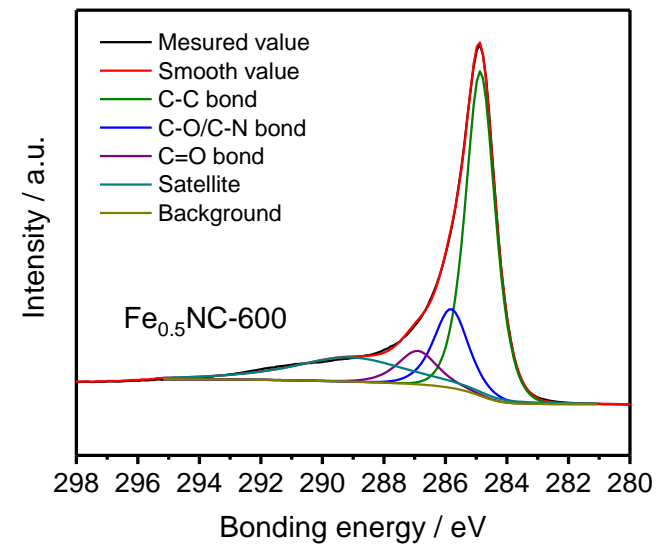

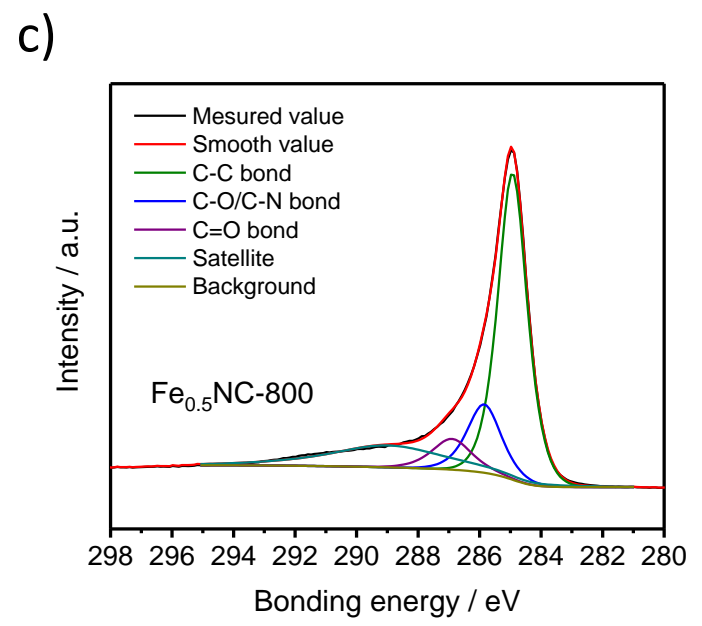

Figure S8. Comparison of the narrow scan X-ray Photoemission spectra at C 1s region for the three catalysts $\mathrm{Fe}_{0.5} \mathrm{NC}$ (a), $\mathrm{Fe}_{0.5} \mathrm{NC}-600$ (b) and $\mathrm{Fe}_{0.5} \mathrm{NC}-800$ (c) 
Supplementary Table 1 | Carbon content determination form C 1s fine XPS scans

\begin{tabular}{|c|c|c|c|c|}
\hline \multirow{2}{*}{ Catalysts } & \multicolumn{4}{|c|}{ Relative atomic ratio / \% } \\
\cline { 2 - 5 } & C-C bond & $\begin{array}{c}\text { C-O/C-N } \\
\text { bond }\end{array}$ & $\begin{array}{c}\text { C=O } \\
\text { bond }\end{array}$ & Satellite \\
\hline Fe0.5NC & 69.56 & 21.92 & 8.52 & 0 \\
\hline Fe0.5NC-600 & 70.29 & 20.00 & 9.70 & 0 \\
\hline Fe0.5NC-800 & 71.59 & 18.73 & 9.68 & 0 \\
\hline
\end{tabular}

Supplementary Table 2 | Iron content determination form Fe 2p fine XPS scans

\begin{tabular}{|c|c|c|c|c|c|c|}
\hline \multirow{2}{*}{ Catalysts } & \multicolumn{7}{|c|}{ Relative atomic ratio / \% } \\
\cline { 2 - 7 } & $\begin{array}{c}\mathrm{Fe} 2 \mathrm{p} 3 / 2 \\
\mathrm{Fe}^{2+}\end{array}$ & $\begin{array}{c}\mathrm{Fe} 2 \mathrm{p} 1 / 2 \\
\mathrm{Fe}^{2+}\end{array}$ & $\begin{array}{c}\mathrm{Fe} 2 \mathrm{p} 3 / 2 \\
\mathrm{Fe}^{3+}\end{array}$ & $\begin{array}{c}\mathrm{Fe} 2 \mathrm{p} 1 / 2 \\
\mathrm{Fe}^{3+}\end{array}$ & $\begin{array}{c}\mathrm{Fe}^{2+} \\
\text { satellite }\end{array}$ & $\begin{array}{c}\mathrm{Fe}^{3+} \\
\text { satellite }\end{array}$ \\
\hline Fe0.5NC & 56.5 & 0 & 43.5 & 0 & 0 & 0 \\
\hline Fe0.5NC-600 & 40.48 & 0 & 59.52 & 0 & 0 & 0 \\
\hline Fe0.5NC-800 & 52.93 & 0 & 47.07 & 0 & 0 & 0 \\
\hline
\end{tabular}

Supplementary Table $3 \mid$ Site density data evaluated from CO sorption of Polyaniline (PANI)-derived pyrolyzed Fe/nitrogen doped porous carbon catalysts for the ORR FeNC (PANI-Fe), FeMnNC (PANIFeMn), MnNC (PANI-Mn) published previously. ${ }^{1}$

\begin{tabular}{|c|c|}
\hline $\begin{array}{l}\text { Catalysts from } \\
\text { reference } 1\end{array}$ & $\begin{array}{c}\text { SD } \\
10^{19} \text { site } / g_{\text {catalyst }}\end{array}$ \\
\hline PANI-Fe & 9.10 \\
\hline PANI-FeMn & 6.81 \\
\hline PANI-Mn & 4.46 \\
\hline
\end{tabular}


Supplementary Table 4 | Site density data evaluated from CO sorption of Polyaniline (PANI)-derived pyrolyzed $\mathrm{Fe} /$ nitrogen doped porous carbon catalysts synthesized in presence of various secondary $\mathrm{N}$ precursors (Urea (Urea), cyanamide (CM), melamine (Mel), nicarbazin (NCB)) published previously. ${ }^{2}$

\begin{tabular}{|c|c|}
\hline $\begin{array}{c}\text { Catalysts from } \\
\text { reference 2 }\end{array}$ & $\begin{array}{c}\text { SD } \\
\mathbf{1 0}^{\mathbf{1 9}} \text { site } / \mathbf{g}_{\text {catalyst }}\end{array}$ \\
\hline PANI-Fe-Urea & $4.52 \pm 0.54$ \\
\hline PANI-Fe-CM & $3.79 \pm 0.31$ \\
\hline PANI-Fe-Mel & $6.68 \pm 0.90$ \\
\hline PANI-Fe-NCB & $2.95 \pm 0.12$ \\
\hline
\end{tabular}


Koutecky-Levich analysis

To account for the mass transport effects, the kinetic current were calculated with the Koutecky-Levich expression according to

$$
\begin{gathered}
\frac{1}{j_{k}}=\frac{1}{j}-\frac{1}{j_{l}}=\frac{1}{j}-\frac{1}{B_{L} \omega^{0.5}} \\
B_{L}=0.201 n F D_{O_{2}}^{2 / 3} v^{-1 / 6} C_{O_{2}}
\end{gathered}
$$

Where $j_{k}$, the kinetic current density at a given potential $\left(0.8 \mathrm{~V}_{\mathrm{RHE}}\right.$ or $0.9 \mathrm{~V}_{\mathrm{RHE}}$ in the present study), is calculated from the measured geometric current density, $j$, and the oxygen-diffusion limited current density at the plateau on the polarization curve, $j_{l}$. In the present study, we set the $j_{l}$ value to the current at a potential of $0.2 \mathrm{~V}_{\mathrm{RHE}}$ well inside the transport limited current plateau both in $0.1 \mathrm{M} \mathrm{HClO}_{4}$, and $0.1 \mathrm{M} \mathrm{KOH}$.

$B_{L}$, the Levich constant.

$\omega$, the rotating speed for RRDE

$n$, the number of electrons transferred during ORR

$F$, the Faradaic constant (96485 $\left.\mathrm{A} \mathrm{s} \mathrm{mol}^{-1}\right)$

$D$, the $\mathrm{O}_{2}$ diffusion coefficient $\left(1.85 \times 10^{-5} \mathrm{~cm}^{2} \mathrm{~s}^{-1}\right.$ for $0.1 \mathrm{M} \mathrm{KOH} ; 1.67 \times 10^{-5} \mathrm{~cm}^{2} \mathrm{~s}^{-1}$ for $\left.0.1 \mathrm{M} \mathrm{HClO}_{4}\right)$

$v$, the kinematic viscosity of the electrolyte $\left(0.89 \times 10^{-2} \mathrm{~cm}^{2} \mathrm{~s}^{-1}\right.$ for $0.1 \mathrm{M} \mathrm{KOH} ; 1.009 \times 10^{-2} \mathrm{~cm}^{2} \mathrm{~s}^{-1}$ for $0.1 \mathrm{M}$ $\mathrm{HClO}_{4}$ )

$C_{O 2}$, the $\mathrm{O}_{2}$ concentration in the electrolyte $\left(1.21 \times 10^{-6} \mathrm{~mol} \mathrm{~cm}^{-3}\right.$ for $0.1 \mathrm{M} \mathrm{KOH} ; 1.38 \times 10^{-6} \mathrm{~mol} \mathrm{~cm}^{-3}$ for 0.1 $\mathrm{M} \mathrm{HClO}_{4}$ )

\section{Reference}

1. Sahraie, N. R.; Kramm, U. I.; Steinberg, J.; Zhang, Y.; Thomas, A.; Reier, T.; Paraknowitsch, J. P.; Strasser, P., Quantifying the density and utilization of active sites in non-precious metal oxygen electroreduction catalysts. Nat Commun 2015, 6, 8618.

2. Leonard, N. D.; Wagner, S.; Luo, F.; Steinberg, J.; Ju, W.; Weidler, N.; Wang, H.; Kramm, U. I.; Strasser, P., Deconvolution of Utilization, Site Density, and Turnover Frequency of Fe-Nitrogen-Carbon Oxygen Reduction Reaction Catalysts Prepared with Secondary N-Precursors. ACS Catalysis 2018, 8 (3), 1640-1647. 